\section{BRUSHING WHITER}

Philips Oral Healthcare has launched a new sonic toothbrush which promises teeth two shades whiter in two weeks. The HealthyWhite toothbrush, set to clean and white mode, is proven to remove everyday stains such as coffee, tea, red wine and tobacco. With HealthyWhite whitening is effortlessly integrated into patients' daily oral care routine. The brush ensures healthier gums, a brighter smile and better overall health.

The brush aims to satisfy the huge increase in demand for tooth whitening. Market research by Mintel showed that sales of tooth whitening products rose to $\mathfrak{E} 37$ million

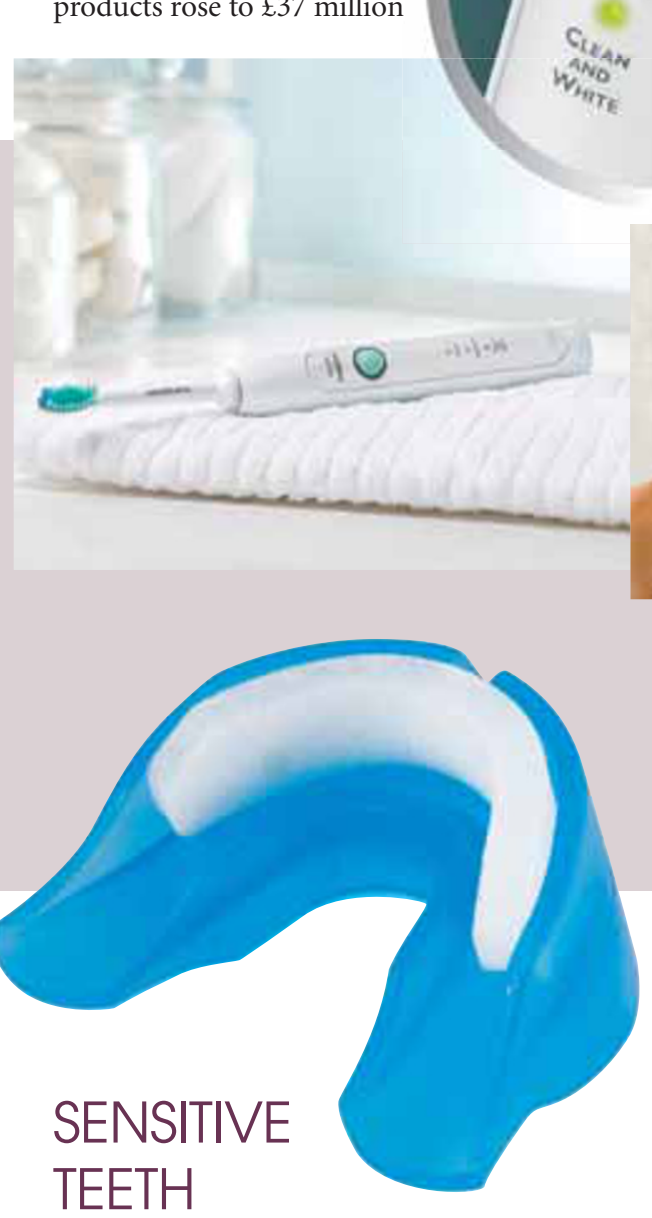

Savodent Sensitive is a new treatment for sensitive teeth, with a single application giving relief for up to a month. It is quick and easy to use. Two active foam strips are placed in a double tray which is then worn for ten minutes per treatment - giving immediate relief from the pain of sensitive teeth. The active ingredient, potassium oxalate, has been shown to be the best formula for occluding exposed dentinal tubules and for reducing pain by modifying nerve excitability.

For further information visit www.swallowdental.co.uk, telephone 01943604408 or email sales@swallowdental.co.uk. last year, and are predicted to increase to $\mathfrak{E} 69$ million by 2010 .

When using the brush's clean and white mode users increase the length of time they brush by a quarter. Additional clean and sensitive settings are also available to allow patients to opt for superior overall cleaning, or a gentle clean if they have sensitive gums and teeth.

The ProResults brush head contributes to superior plaque removal and improved gum health. The brush is also proven to be safe and gentle on braces, dental work, veneers and implant materials.

Telephone 08000567222 or visit www.sonicare.co.uk.

\section{BRIGHTEN UP WALLS}

Buying art for your practice is an easy way of creating a friendly and comfortable atmosphere for clients. Easyart's online shop allows you to browse through a range of more than 100,000 images, including photographic prints, etchings, canvases and limited editions. Popular prints for practices include modern landscapes and still life images. These can be calming, and appeal to all ages. Images come from every period and style. Easyart also offers a free consultancy service to business customers, and a framing service. Framed and canvas images

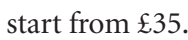

Contact Easyart.com on 0207409 0575, clare@easyart.com, or visit www.easyart.co.uk. 